\title{
ENSAYISMO Y DESTINO EN ENRIQUe MOLINA*
}

\section{Carlos Ossandón Buljevic**}

\section{Resumen}

El artículo examina la discusión que el filósofo Enrique Molina entabló con Bergson en los inicios del siglo XX, la crítica a la "intuición" como método de conocimiento, la defensa de la razón, los vínculos entre Molina y la literatura, el despliegue de una "política de la filosofía" y la forma como el autor chileno fue estructurando una filosofía personal, cifrando aquí y en la modalidad ensayística una significación, un lugar en el mundo, un "destino".

Palabras clave: Ensayo, Filosofía, Henri Bergson, Enrique Molina.

\section{ESSAY WRITING AND DESTINY IN ENRIQUE MOLINA}

\begin{abstract}
The article examines the discussion initiated at the beginning of the 20th century between the philosopher Enrique Molina and Bergson, the critique to "intuition" as a method of knowledge, the defense of reason, the links between Molina and the literature, the deployment of a "politics of philosophy " and the way in which the Chilean author produced a personal philosophy coding a significance both here and in the essay as a genre, as a place in the world, as a "destiny".
\end{abstract}

Keywords: Essay, Philosophy, Henri Bergson, Enrique Molina.

Recibido: 15-12-2015

Aceptado: 21-01-2016

* El presente artículo forma parte del proyecto FONDECYT N 1150278 , titulado Filosofía y literatura en América Latina (fines del siglo XIX y primeras décadas del XX).

** Chileno. Doctor en Filosofía y Letras, Universidad de Gante, Bélgica. Profesor Titular de la Universidad de Chile, Santiago, Chile. cob2002@u.uchile.cl 
“...se puede decir de nuestra época que es, en cierto sentido, una edad sofística, una de aquellas edades que señalan el fin de un ciclo de idea y anuncian la aurora de uno nuevo" Enrique Molina (1916)

El presente artículo examina parte de la obra del filósofo chileno Enrique Molina Garmendia (1871-1964), en particular sus textos más tempranos. Interesa sobre todo relacionar las articulaciones y conexiones propias de su obra, las inflexiones que caracterizan sus primeros textos filosóficos, y el modo como este autor construye un programa o un lugar para la filosofía, una "política de la filosofía". Con este fin nos detendremos en la discusión que el filósofo chileno entabló con Henri Bergson, en su crítica a la "intuición" como método de conocimiento, en la relación que mantuvo con la literatura y en la forma como fue estructurando una filosofía personal, un estilo reflexivo y existencial a la vez, cifrando aquí o en la modalidad ensayística una significación, un lugar en el mundo, un "destino". Cuestiones estas últimas que se harán ciertamente más visibles en el curso posterior o más "maduro" de su obra.

¿A qué terrenos nos puede conducir esta búsqueda? ¿Con qué inesperadas e "inactuales" temáticas o perspectivas nos podremos encontrar? ¿Qué espacio le concede Molina a la filosofía en el contexto de la pervivencia del positivismo y la simultánea irrupción del pensamiento de Bergson? ¿Cómo comienza a fraguarse en este escenario la figura del "autor", algo inédita en el campo filosófico latinoamericano? ¿Qué distancias y acercamientos se comprueban entre filosofía y literatura respecto de esta figura? Como un modo de abordar estas preguntas intentaré ligar la crítica que hace el joven Molina a la filosofía de Bergson con los nuevos posicionamientos que para la filosofía se dejan ver en el pensador chileno.

\section{En busca de una expresión}

En una escena donde el positivismo comenzaba a mostrar -aunque aún tímidamente- sus limitaciones, la escolástica poco servía para explicar las nuevas realidades, el "espiritualismo" de la segunda mitad del XIX se dispersaba o no lograba proyectarse más coherentemente ${ }^{1}$, la

1 Arturo Andrés Roig y Arturo Ardao reconocen bajo el nombre de "espiritualismo" un amplio movimiento que expresó inspiraciones krausistas, emersonistas y eclécticas con Víctor Cousin. 
implementación política o el afán pedagógico de la filosofía ya no eran suficiente ni agotaban todas las posibilidades de un quehacer que debía ahora enfrentar nuevos desafíos de comprensión cultural o epocal, ¿qué nuevas configuraciones debía tomar la filosofía en estos comienzos del siglo XX? La pregunta se hace pertinente e incluso imperiosa en un contexto que involucraba otros saberes y sensibilidades que buscaban formas más autónomas de instalación en el mundo, instigando para ello objetos, campos o prácticas más o menos independientes, contrariando el célebre "todas las verdades se tocan" proferido por Andrés Bello en 1843 con ocasión de la inauguración de la Universidad de Chile.

La respuesta no se ofrecía fácil para Molina, dado que debía transitar en medio de complejas corrientes de pensamiento tales como el pragmatismo, el positivismo, el evolucionismo, el cientificismo que preñaba varias de estas corrientes (Horkheimer 77), el neokantismo, las nuevas orientaciones vitalistas, así como -en otro registro-entre los efectos embriagadores que no dejaban de ser seductores para Molina que ya contaba con cierta producción literaria, a los que invitaban ciertas poesías de Walt Whitman o el inquietante Journal intime del escritor suizo Enrique Federico Amiel (Molina, La filosofía de Bergson 319)². Debía moverse, además, entre tópicos igualmente complejos tales como las tensiones entre determinismo y libertad, entre los temas del evolucionismo y sus críticos, entre la intuición y las formas de conocimiento predominantes en la ciencia, entre las formas de captación del mundo de la filosofía y las disecciones de las ciencias y, en un terreno más específico, entre una nueva concepción de la movilidad y lo engañoso que podía ser el conocimiento usual o el cine, que nos hace imaginar el movimiento, como lo había adelantado Bergson, a través de "una serie de estados inmóviles" (La filosofía de Bergson 316)3. Con más o menos diálogo con estos tópicos y con las corrientes de pensamiento nombradas, y en el marco -como decíamos- de un inicial y no siempre nítido proceso de división del trabajo intelectual

2 Uso las Obras Completas de Enrique Molina Garmendia (1994) de las Ediciones Universidad de Concepción. Se trata de la compilación, revisión y estudio preliminar realizado por Miguel Da Costa Leiva.

3 Para Bergson el conocimiento usual -y también el conocimiento científico- parte de la inmovilidad" /.../ y por un ingenioso arreglo de inmovilidades recompone una imitación del movimiento que sustituye al movimiento mismo" (Bergson, Introducción a la metafísica y La intuición filosófica 137). El ensayo de Bergson que citamos (La intuición filosófica) fue originalmente una conferencia pronunciada el 10 de abril de 1911 para el Congreso de Filosofía de Bolonia. Y el otro que lo precede Introducción a la metafísica apareció en 1903 en la Revue de métaphysique et de morale. 
que afectaba a distintas disciplinas, Molina sentirá que forma parte de su "deimon" la necesidad de dotar a la filosofía de un lugar o de un espacio que haga del raciocinio su elemento, del argumento o la crítica sus condiciones naturales, cuestiones estas últimas que pudiesen explicar el rechazo al irracionalismo que cree ver en la filosofía de Bergson.

Con la intención de no confundir la filosofía con la psicología, tal como se habría dado en los tiempos iniciales del Instituto Pedagógico ${ }^{4}$ como tampoco de asimilarla sin más a la pedagogía, sin dejar de valorar el aporte de la sociología (de Lester F. Ward, más particularmente), y evitando hacer del cultivo de la razón filosófica el correlato directo, casi sin mediación, de la organización social o política, Molina hará compatible la búsqueda de una determinada "expresión" o estilo, de una cierta ecuación entre el "qué" y el "cómo" al decir de Walter Benjamin, con la reivindicación de un ámbito discursivo que identifica con la filosofía.

Lo que decimos tiene que ver con la apuesta que hace Molina por contar con una "obra" que sea el resultado de sus lecturas, de la precisión de ciertas nociones básicas (la noción de "espiritualidad" es aquí central y articuladora), del diálogo con otros autores, del contacto con sus contemporáneos, de los temas que le apasionaron de su presente, de sus vivencias como profesor o como un habitante más del mundo que le tocó en suerte. Esta obra no podía ser sino, entonces, el correlato de una experiencia personal, cuestión que une a Molina no solo con esa vieja tradición que asimilaba saber con sabiduría sino también con otros escritores de su época -citemos solo a Rubén Darío- para quienes la modernidad había dejado de ser aquel "proyecto" moderno-civilizador que comprometió a importantes figuras del XIX -como Domingo Faustino Sarmiento-, para transformarse en este fin del siglo XIX e inicios del XX en una "experiencia", que como tal removía vocaciones subjetivas o núcleos íntimos (Ossandón, 2008) y que, para Molina, no podía expresarse solo en el ámbito literario, desatendiendo su expresión filosófica.

Para llegar a contar con una obra -si es que se puede hablar de la plena realización de tan difícil objetivo-, Molina experimentó un proceso de formación o de decantación que se hace visible desde sus primeros

4 Como se sabe, Molina, junto con su amigo Alejandro Venegas (el cuestionado Dr. Valdés Cange, aquel formidable crítico de Sinceridad. Chile intimo en 1910), formó parte de la primera generación del Instituto Pedagógico. Ver Enrique Molina (1939), Rolando Mellafe / María Teresa González (2007) y Marcelo Pérez (2015). 
libros hasta sus últimos, todo lo cual queda más existencialmente fijado en su autobiografía Lo que ha sido el vivir. Dicho desde otro ángulo, habrá que aceptar que la construcción de una obra reconocible, de un decir que se puede precisar, o de una escritura o de un estilo que lleva consigo un pensamiento que con sus aciertos y límites pone en tensión preguntas fundamentales para la condición humana, no se dio graciosamente ni de una vez en Molina. De aquí nuestro interés, como ya se ha señalado, por el joven Molina (que tiene, en rigor, algo más de 40 años): de aquel que ha logrado en ese preciso momento de su vida definir por fin una vocación que privilegia la enseñanza y la filosofía por sobre la abogacía (Molina, Confesión personal 400). En estas primeras incursiones filosóficas de Molina emerge una vocación argumentativa y polémica que nos permiten acceder a una cierta "cocinería", al modo como se va elaborando un proyecto filosófico o una figura que, como la del "autor", no era entonces muy corriente en el campo filosófico latinoamericano o nacional. Una figura que se relaciona o coexiste con emergencias parecidas en otros campos, tal como se aprecia en el dominio literario en el seno de las sensibilidades modernistas y vanguardistas de fines del XIX y las primeras décadas del XX.

\section{La crítica a Bergson}

Si nos detenemos en el primer texto sobre Bergson publicado por Molina en $1916^{5}$, una de las cuestiones que llama la atención es la relación que se establece entre las críticas que organiza contra el filósofo francés y el esfuerzo bastante persistente en Molina de dar peso y consistencia a un lugar de enunciación que sea claro, sin equívocos y que pueda operar como criterio universal y normativo a la vez. De entrada, el texto que destacamos se nos presenta como una suerte de guía para la filosofía que se había de practicar.

No es mi intención en esta presentación, como ya se ha dicho, abordar estas cuestiones separando a Molina, o su crítica a Bergson, de su particular posicionamiento en el escenario filosófico latinoamericano o chileno. Lo que no significa, obviamente, que la tarea de examinar a este pensador

5 Molina publica tres textos referidos a Bergson, con pocas diferencias entre ellos. Estos son: "La filosofía de Bergson" (1916), "Dos filósofos contemporáneos: Guyau-Bergson" (1925), "Proyecciones de la intuición. Nuevos estudios sobre la filosofía bergsoniana" (1935). En Obras Completas, Vol. I y II. Ver también los estudios preliminares de Miguel Da Costa Leiva para esta edición de la obras de Molina. 
más cerradamente a la luz de lo que vio -y sobre todo no vio- de Bergson no sea fructífera, como ya nos lo demuestran distintas aproximaciones que pudiesen inspirar esta tarea: desde la comprensión de la intuición como un elaborado "método" según lo recalcó Gilles Deleuze (1987) y no sin mediaciones como lo creyó Molina, hasta la constatación tampoco percibida por nuestro autor de la ampliación que hace Bergson de la "experiencia", según lo destaca el chileno Miguel Ruiz (2013) en un muy completo trabajo reciente, por citar dos textos que he tenido a mi alcance.

En torno a la temática de la "intuición" parecen concentrarse distintas aristas que interesan a la presente exposición. “¿Tendrá la intuición -se pregunta Molina- la llave de los problemas fundamentales que preocupan a los hombres?" (La filosofía de Bergson 312). ¿Habrá que aceptar, tal como Molina cree verlo en Bergson, que la intuición "constituye una especie de recinto sagrado que no podemos alcanzar" (314) pero del cual, según el filósofo francés, no podríamos prescindir si lo que se busca es penetrar en la interioridad de lo real? ¿Podemos aceptar sin más que la intuición "se sustrae a todas las condiciones de tiempo y de lugar" (315), tal como lo había planteado sorprendentemente Bergson en su conferencia de 1911, al diferenciar el elemento "constitutivo" de una filosofía de su "medio de expresión" que sí dependería de distinta manera de su circunstancia? (La intuición filosófica 106-107).

No se trata, según Molina, de negar ni la genialidad ni la privilegiada pluma de Bergson, pero sí de ponerse en guardia ante un tipo de conocimiento de formas vagas e impenetrables que no se expresa en proposiciones, que desconfía de los procedimientos propios del análisis, y que conduce finalmente a la incomunicación y también al solipsismo. Aun cuando el texto de Bergson al cual alude Molina evita el encierro simple, único y sin mediaciones en la subjetividad, en la medida que es precisamente la exploración en la profundidad propia la que permite penetrar y recobrar el mundo (Bergson, La intuición filosófica 132-133-135-140-141), es claro que una de las mayores incomodidades que Molina expresa se relaciona con aquello que entraba o dificulta el desarrollo mismo de la filosofía, que es para él por naturaleza comunicable y, por lo mismo, compartible. Se podría aventurar que, en el marco de las precariedades de la filosofía en América Latina, del esfuerzo por hacer confluir las voluntades, o de contar con un mayor reconocimiento público, el hecho de contar con un tipo de expresión clara, sin misterios, que facilitase la comunica- 
ción y ciertos consensos básicos, se presentó a los ojos de Molina como lo que había que estimular.

La objetividad de las relaciones de causalidad, de un "mecanismo" no repetitivo pero igualmente objetivable y comunicable, no religioso, como podía ser, en cambio, el "finalismo" (Molina, La filosofía de Bergson 324-325-326); la extensión correlativa de "los métodos lógicos de la inteligencia" (319); así como -en otro nivel-la necesidad de compartir una cierta ilustración, unos métodos de enseñanza, de reconocer una lengua común, son todas cuestiones, estas últimas, que están presentes en su texto Filosofía americana de 1914 y que en el joven Molina van articulando un piso básico comunicable y compartible que debería facilitar, si no una finalidad ya trazada, (Molina combate, al igual que Bergson, el "finalismo") sí el "mejoramiento" de la vida humana o el "meliorismo", según expresión del sociólogo Lester F. Ward (Molina, Filosofía americana 234).

No se podía renunciar, pues, al pensar y al método discursivo. La reacción de Bergson contra "el intelectualismo exagerado" (Molina, La filosofía de Bergson 371) no podía llevarnos a unos encantamientos, a unas oscuridades o misticismos que pusiesen en entredicho lo que la ciencia había conseguido, ni menos aún todo el dispositivo raciocinante y comunicacional basado en verdades, conceptos, pruebas, y no en meras creencias (311). Había que contar, entonces, con ese "vicio original de la inteligencia" (319) tan denostado por Bergson. Era preciso, igualmente, criticar las "sutilezas del escepticismo" (311) que se manifestaba en un pragmatismo que, aun reconociéndole su inmanencia y la valorización de la experiencia, negaba "la existencia de verdades objetivas" (311), asimilando lo verdadero a lo útil o solo a lo que "sirve para la acción" (311). A la defensa del dispositivo raciocinante se le une, en este último punto, el resguardo, más allá de los requerimientos siempre apremiantes de la acción (ámbito que, como es evidente y sabido, Molina no soslayará), de un plano irreductible, que en cierto sentido se sostiene a sí mismo, y que es preciso atender con toda la seriedad posible: la objetividad del mundo o el velado recurso a su preexistencia y su expresión en unos enunciados que no son "copia fiel" (la verdad se expresa "de una manera simbólica", dice Molina, (La filosofía de Bergson 312),y cuya validez habrá que examinar a la luz de la razón y de sus operaciones (311). Se podría decir que Molina, tal como afirmará Adorno varios años después en otro escenario, procurando corregir lo que Lukács parecía haber olvidado, a saber, 
la precisión de los rasgos propios del ensayismo filosófico, no solo no confiará en la "intuición intelectual" sino también, al igual que Adorno, tampoco en su mezcla con el "concepto" (Adorno 15-16).

La "intuición" no podía reemplazar al "discurso", la visión directa o el "contacto", como dirá más bien Bergson (Bergson La intuición filosófica 108), no podía negar las posibilidades de la mediación o del rodeo silogístico, como tampoco la síntesis podía desbancar al análisis. Era la propia filosofía y sus procedimientos, que ya Rubén Darío en su célebre Azul... de 1888 había asimilado a un asno condescendiente con el poder, la que aquí jugaba su supervivencia7. Tal como lo había vivenciado la literatura de fines del XIX, ahora parecía llegado el turno para la filosofía. Si el "modernismo literario" buscó salvar a la poesía amenazada por el materialismo reinante, descubriendo las posibilidades experimentales o creativas del propio órgano poético, la filosofía, si deseaba ser algo más que sierva, "ancillae", debía hacer otro tanto o al menos evitar su asimilación sin más a otros saberes, objetivos o lenguajes. En esta delicada coyuntura no era la confusa figura del "poeta de lo abstracto" (Molina, La filosofía de Bergson 323) la que podía orientarnos, sino más bien la que se apresta al vuelo filosófico sin dejar de mantener los pies en la tierra y, sobre todo, sin renunciar al dominio de lo inteligible o de un saber que debe expresarse necesariamente en proposiciones que tengan "el carácter psíquico de una representación" (318). El chileno no desea ser ni poeta ni místico, pero sí filósofo, aun cuando esta opción lo apartase de aproximaciones más "sim-patizantes" como las que proponía una ofensiva que, sin negar la validez o la irreductibilidad de la mirada filosófica (Bergson la defiende expresamente), buscaba discurrir por fuera del criticismo kantiano y sus continuadores a cambio de un embrujo escritural difícilmente resistible.

6 Más adelante Molina repondrá, tal como recuerda Da Costa Leiva, el valor de la "intuición". Esta revalorización forma parte de los nuevos derroteros que toma su pensamiento.

7 En el cuento "El sátiro sordo", el asno junto con la alondra son los consejeros áulicos del lascivo y alegre sátiro: mientras esta última perdió su prestigio a causa de la sordera del sátiro, el asno le servía para cabalgar. Experto en filosofía, aunque "no había conversado con Kant", el asno será quien desaconseje la presencia de Orfeo y de su música en los reinos de aquel "viejo rey de su selva". Una visión más amplia que reconoce y ordena las varias poéticas filosóficas presentes en la obra de Darío se puede consultar en la introducción de Alberto Acereda: Rubén Darío, Poemas filosóficos (2007). 


\section{Autor y campo del saber}

Ahondemos un poco más en lo que acabamos de adelantar. ¿Porqué era importante para Molina defender una aproximación que se apoyaba en la fecundidad probada de las "representaciones" o en un tipo de conocimiento que, en lugar de fundirse con las cosas, pudiese rastrear más bien "las explicaciones de las cosas"? (Molina, La filosofía de Bergson 317)¿Qué lo llevaba, por otra parte, a no dejarse conducir, como lo insinuaban creaciones literarias recientes, hacia una atrayente y envolvente solidaridad universal e infinita, prestando el "alma a las estrellas, al bosque, al mar"? (319) ¿Qué hay en esta renuncia a este baño de "quietud deliciosa" (319), e incluso a su propia producción literaria (había ya publicado 10 cuentos), que pudiese tener relevancia para el desarrollo de la filosofía en América Latina o Chile? ¿En qué sentido un cierto perfil de lo que debieran ser la comunidad filosófica y el filósofo individual se juega en la textura misma de la crítica a Bergson? ¿Es legítimo precisar aquí, en el propio gesto crítico, una determinada politicidad, es decir, siguiendo libremente a Rancière, una cierta modalidad de vínculo entre la filosofía en tanto que filosofía, sus propias inscripciones, y la comunidad a la cual se debe o se aspira? ¿Estamos insinuando que en medio de la supuesta inutilidad de la escritura filosófica se deja ver una política práctica de la filosofía?

Estas preguntas nos permiten adelantar una interpretación que se apoya en el nexo que suponemos existente entre la vocación filosófica del chileno, la lectura que hace de Bergson, y las demandas de desarrollo de un campo del saber que hemos creído operante en el seno mismo de sus formulaciones críticas. Dicho de otra manera, quisiéramos saber si es posible comprobar, en la propia exterioridad o positividad de los textos del joven Molina, unas inflexiones, unas advertencias o unas repeticiones que dan cuerpo no solo a un "concepto" de filosofía sino también, y por esa misma vía, a una "política de la filosofía".

8 Me estoy sirviendo con licencia de esa "política de la literatura" que examina Jacques Rancière. Esta noción no refiere a la política que hacen fácticamente los escritores, a la forma como "representan" los conflictos sociales o su inserción en ellos, sino antes bien al modo como las escenificaciones, operaciones o desplazamientos de las prácticas literarias actúan o intervienen en la política como práctica colectiva o, más precisamente, en el "común" sensible. Como se verá en lo que sigue, en el presente análisis hemos buscado hacer confluir dos entradas, la primera de ellas de inspiración ranceriana: a) la consideración de los énfasis, giros o reposicionamientos que se dan en el propio discurso filosófico y la resonancia, figuración o más bien reinscripción de estos en un "común" sensible que, en los modernos tiempos de Molina, requería diferenciar lenguajes, sensibilidades y "campos"; b) la consideración de una idea de sociedad que se deja transparentar en los textos de Molina y que muestra una relación de complicidad entre la filosofía que se postula y la sociedad que se desea. Si unimos ambas entradas, se verá que la política transcurre tanto en la filosofía como por sus contenidos. 
Es evidente que no es poca el agua que ha corrido bajos los puentes entre el periodo de la Independencia o de la fundación republicana y los comienzos del siglo XX. La escritura ya no cree estar delante de ese "vacío" del periodo fundacional y que busca "llenar" (Ramos, 2003) o -en una mirada histórica más amplia-tampoco se enfrenta a esa ficción de la "página en blanco", "disponible", sobre la cual había que instalar el "orden letrado", unas marcas inéditas nunca vistas en el Nuevo Mundo (Sánchez, 2013).En el escenario de una "crisis" que tocaba prácticamente todos los aspectos de la vida, que presenciaba así la "disolución" del siglo XIX (Federico de Onis), y que comenzaba a mostrar, por otra parte, la configuración de un nuevo espaciamiento cultural y social, ¿no cabía buscar un nuevo posicionamiento para la filosofía, enfrentada a una modernidad que avanzaba sin mayores miramientos, que problematizaba los arrimos tradicionales y también las formas más institucionales de relación entre cultura y poder; una modernidad desigual y contradictoria que generaba unas desorientaciones sociales y existenciales que el siglo XIX no había conocido con tal radicalidad ${ }^{9}$ ¿No era preciso reexaminar el aporte y el lugar de la filosofía en un escenario que asistía a la irrupción de nuevas e inquietantes figuras: Nietzsche, Schopenhauer, Tolstoi, Marx (El Capital es traducido al español para América Latina a fines del XIX) y donde hasta el imperio de la razón parecía tambalear con Bergson?

Si bien el dominio literario será -creo- más sensible que el filosófico a las graves cuestiones que planteaba aquel crítico clima cultural o epocal, y que Molina-nunca ausente de su entorno más cercano-no parece ser la consciencia más aguda de estos procesos ni llega tan lejos como Rodó con su Ariel (1900) ni tiene la originalidad crítica de Mariátegui, hay que reconocer que sus primeros textos muestran un interesante sentido de ubicación al subrayar un nuevo y más "autónomo" lugar para la filosofía; un lugar que, aunque todavía afincado en un positivismo o cientificismo cuyas raíces se remontaban a la segunda mitad del siglo XIX, debía orientarse ahora en un sentido distinto y sin conminaciones políticas directas. Una filosofía que ya no se reconocía como instrumento o base en la construcción o salvaguarda del orden deseado (como lo había sido el positivismo precisamente, más visiblemente en México o en Argentina).En la defensa de un ámbito filosófico que operase sin un juez

9 Es particularmente expresivo en esta dirección el "Nadie dijo nada, nadie dijo nada" del poema Nada (1904) de Carlos PezoaVéliz. 
exterior que lo condujese, no había porqué no atender simultáneamente -aunque fuera de una relación "orgánica" con la política- demandas varias, no aislando la filosofía o las humanidades de los contextos que las requerían ${ }^{10}$. Había igualmente que dialogar y no solo aplicar lo que venía de la tradición filosófica, y de este modo "ensayar" aproximaciones que fuesen singulares, lo que suponía dar otro espesor a las cuestiones propiamente teóricas: ya no era permitido quedar al margen de la discusión más exigente en el plano filosófico o de la especulación como tal ${ }^{11}$.

En el escenario que describimos ya no bastaba la docencia ni el compromiso político o militante: ahora había que escribir. Esto es decisivo en Molina. Su obra es precisamente la expresión de un pensamiento y de una subjetividad que es a la vez escritura. "A mi espíritu -dice Molina- lo embargaba la emoción de trascender la función estrictamente escolar y expresarse en el verbo hablado y escrito" (Lo que ha sido el vivir...145). De un modo parecido a lo que comenzaba a apreciarse en otros campos, aunque ciertamente con ingredientes propios, más allá del ya viejo paradigma de la "república de las letras" aunque conservando aspectos del clásico "bien decir" bellista, la filosofía en Molina va a ensayar-dando ahora una mirada más amplia de su obra-un tipo de validación que, junto con concebir a ésta como un acontecimiento del pensar-escribir, incluye en su singularidad la emergencia de un "autor". Se trata de una atrevida apuesta de Molina que supone la no fácil fijación de un "locus", de una modalidad de enunciación, de un mayor control sobre el discurso o, mejor aún, de un cierto modo de ser del discurso mismo, en términos de Foucault (2001).

Es evidente que este nuevo hablante filosófico se construyó de a poco, que en esta trayectoria sus representaciones no son lo único a destacar a pesar de la valorización que sobre ellas hizo Molina, alcanzando esta trayectoria uno de sus puntos más altos en De lo espiritual en la vida humana,

10 Son ilustrativas en esta dirección las críticas de Molina a las tesis del historiador Francisco Antonio Encina en el contexto del Congreso Nacional de Educación Secundaria de 1912 (cfr. Pozo). Se podría decir, en términos más generales, que en la relación que establece Molina entre la precisión de un lugar para la filosofía y el diálogo con la diversidad de manifestaciones propias del mundo, se cifra uno de sus aportes más interesantes. Contribuye así a destrabar por adelantado aquella perspectiva o modalidad de trabajo que asocia el desarrollo de la filosofía "profesional" con la desafección práctica por los problemas del presente o del entorno más cercano.

11 La lectura que hago de Molina se aparta de la visión que respecto de los "fundadores", también llamados "patriarcas" (entre los cuales se encuentra Molina, en la clásica lectura de Francisco Romero), expresó Francisco Miró Quezada: para ellos -dice- "la filosofía europea fue principalmente un "hermoso y fascinante paisaje" (59), / .../ uno que se contempla o admira "desde lejos" (60) / ... / y en tanto concebida como producto acabado "no tienen ni pueden tener ninguna injerencia" (49). 
cuya primera edición es de 1937, y en su Confesión filosófica que se publica en 1942.Hay que recalcar que este proceso supuso una relación más horizontal o no puramente reverencial con la tradición y las novedades de la filosofía europea o norteamericana, como también que la emergencia de esta nueva figura del "autor" significó, en la práctica, superar la indistinción entre política y cultura, ir más allá de la incorporación a un sujeto nacional o continental o de la urgencia por proponer reformas culturales o políticas, aspectos todos importantes de la ensayística decimonónica (Lagmanovich, 1984). Todo esto sin que la "autonomía" ambicionada para la filosofía, en la distancia que establece respecto de los referentes nombrados, no deje de expresar una política, un determinado modo de relación o de inserción en el mundo moderno.

Encarnando un humanismo abierto y de viejo cuño, no alejado de una cierta mundaneidad, de la polémica, del diálogo con los lectores (sus "confesores" los llama) y de unas angustias existenciales que no teme expresar (Molina, 1942-1994), la nueva figura del "autor" es ciertamente inseparable de los rasgos o formas que va tomando un discurso cada vez más advertido de sí, de su diferencia respecto de la modalidad didáctica o de aplicación, y de la necesidad de precisar una mirada cuyo sesgo inequívocamente filosófico no le impide franquear límites o dialogar con un amplio abanico de autores. Junto a sus trabajos sobre Nietzsche, Heidegger o Sartre, o las traducciones de Kant, están también sus referencias a Shakespeare, Goethe u Oscar Wilde, por un lado; y a José Enrique Rodó, José Ingenieros, Leopoldo Lugones (con quien tendrá una dura polémica) o Gabriela Mistral, por el otro.

Me atrevo a sostener que esta apuesta está ya en ciernes en el joven Molina. Así en las obras de este periodo, junto a las incomodidades que le suscita un filósofo que considera oscuro, irrumpen los primeros rasgos de una subjetividad que busca inventarse y reconocerse en lo que dice. Una subjetividad que entretejida en su decir -contando con esta mediación-, busca desde temprano acceder a ese "momento crucial del crítico" destacado por Lukács: "el momento de su destino" o de su posición ante el mundo, que se da cuando este entrejido, cuando la conjunción entre lo experiencial y lo discursivo, entre el "alma" y la "forma", logran una estabilización que nunca fue definitiva para quien se definió como un "buscador de caminos" (Molina, Confesión filosófica... 490). 


\section{La filosofía como programa y la espiritualización como destino}

No quiero dar la impresión, a pesar de lo dicho, que el interés de Molina fue "demoler" a Bergson. No hay contra él ninguna particular ojeriza ni tampoco lo asocia a ninguna forma de decadencia, tal como lo estaba haciendo en esos mismos años el muy belicoso Julien Benda en Francia (Norberto Bobbio, 1998). Tan elocuente como la crítica a Bergson son las inflexiones y constantes repeticiones del joven Molina. En la crítica a la muy animada y coloreada "duración pura", refractaria, según Bergson, "a la ley y a la medida" (Bergson, La intuición filosófica132) o a ese "deus ex machina" que constituye para Molina el misterioso "impulso vital original" bergsoniano (La filosofía de Bergson 347), nuestro autor insiste una y otra vez, casi hasta el cansancio, en la validez de las definiciones y de las explicaciones lógicas, de las representaciones y de las categorías, por sobre incomunicables inmersiones en abismales flujos. En la repetición de los tópicos que estructuran su crítica no he creído ver una mera extralimitación discursiva, ni tampoco el afán de mostrar las distintas aristas de estos tópicos. ¿Acaso Molina-nos preguntamos- enmascara otra cosa? A mi modo de ver, lo que este proceder muestra -en el estilo humanista, abierto y dialogante de Molina- es el carácter programático de su discurso crítico. El chileno busca provocar un efecto en el lector. Dicho sintéticamente, este programa reza así: si Ud. desea hacer filosofía no puede prescindir de la simbolización o de la explicación conceptual; esto es lo que le permitirá construir obras filosóficas y no poemas como La evolución creadora del "poeta-filósofo" francés (La filosofía de Bergson 353).

Esta clausura sintetiza dos tendencias complementarias, no opuestas en Molina: la de hacer filosofía y no otra cosa, por un lado, y la de hacer la filosofía que el presente requiere, por el otro. Ella trae, además, en sus entrañas-podríamos decir-, una determinada visión de la sociedad: equilibrada, igualmente racional y alejada de cualquier ciego impulso. Una sociedad que debiera desconfiar de lo quimérico, de lo "absolutamente nuevo" (Molina, La filosofía de Bergson 326), de la indeterminación incontrolada o de las soluciones imprevisibles. Una sociedad que tendría que desarrollar no unas libertades intuitivas, solo sentidas o íntimas, o que reinen, en el decir de Kant, en "la región de los noúmenos" (370), sino más bien aquellas fenoménicas "libertades empíricas y prácticas que interesan a los hombres" (370). Molina está 
pensando en libertades que "consisten en posibilidades de hacer y de pensar que se definen y concretan", tales como "la libertad de conciencia, los diversos derechos en todas sus formas, y las limitaciones que hay que señalar a las mismas libertades en atención al interés común" (370). Una idea de sociedad -se puede deducir- que se enmarca dentro de los parámetros occidentales y modernos: libertad de conciencia y no censura, derechos y no servidumbre, interés común y no mera extensión del interés individual. Un espíritu laico, no confesional, quizá entre republicano y liberal, no distante del clásico vivere civile o de la participación ciudadana, es lo que se deja traslucir.

Para terminar, digamos que la sociedad que se postula se completa con la atención que se debe a lo que Molina llama el "espíritu". Una noción que se confunde con la herencia lingüística e intelectual, con sus aspectos que le son más genuinos o propios (361), que alude a las más elevadas funciones: "la verdad, la belleza, la justicia, el amor" (361), así como a lo más personal, creador y hondo de nuestra vida interna (361362-365). La "espiritualidad", en sus distintas manifestaciones o fases, remarca, es "el fin supremo de la vida humana" (362) y también-agreguemos- el fin que se auto impuso el propio sujeto de la enunciación. Este es un aspecto decisivo y que se hará muy nítido más adelante en su obra, desprendido ya Molina de buena parte de los dejos positivistas o cientificistas que exhibió en sus textos más tempranos. En la "espiritualización" de su propia vida, no sin a veces dramáticas tensiones, se explica, según Mario Rodríguez Fernández, el núcleo existencial más importante de Molina (Molina, 2013). Será en este núcleo precisamente, ya presentido por el joven Molina, donde parece jugarse un "destino", una significación, un punto de vista, un lugar en el mundo, no disociable de la posibilidad siempre huidiza de encuentro y revelación a la vez entre la experiencia y la forma que irremediablemente se le adosa (Lukács, 1975). En la pregunta “¿He realizado mi vida espiritual?"(Lo que ha sido el vivir... 319), Molina cree así encontrar, no sin razón, la clave o el resumen de su vida y obra. 


\section{Referencias Bibliográficas}

Adorno, Theodor W. "El ensayo como forma". Notas de literatura. Barcelona: Ariel, 1962.

Anderson Imbert, Enrique. La originalidad de Rubén Darío. Buenos Aires: Centro Editor de América Latina, 1967.

Ardao, Arturo. Espiritualismo y Positivismo en el Uruguay. Uruguay: Universidad de la República, 1968.

Benjamin, Walter. El origen del drama barroco alemán. Madrid: Alfaguara, 1990.

Bergson, Henri. Introducción a la metafísica y La intuición filosófica. Buenos Aires: Ediciones Leviatán, 1956.

.La pensée el le mouvement. Essais et conférences. (Articles et conférences datant de 1903 à 1923). 2003. Web. 11 Nov. 2015.

Bobbio, Norberto. La duda y la elección. Intelectuales y poder en la sociedad contemporánea. España: Paidós, 1998.

Cerda, Martín. La palabra quebrada. Ensayo sobre el ensayo. Chile: Ediciones Universitarias de Valparaíso, 1982.

Darío, Rubén. Azul...y poemas. Selección y prólogo de Hugo Montes B. Chile: Editorial Andrés Bello, 1996.

.Poemas filosóficos. Edición, introducción y notas de Alberto Acereda. Madrid: Ediciones Hiperión, 2007.

Deleuze, Gilles. El bergsonismo. Madrid: Cátedra, 1987.

Fielbaum S., Alejandro. "Bajo la piel de las ideas. Ensayismo y escritura filosófica en Alejandro Korn". Congreso Internacional El ensayo en diálogo: diálogo sobre el ensayo. UNAM. Octubre 2015. Ponencia.

Foucault, Michel. “Qu'est-ce qu'un auteur?” Dits et écrits.T. I. France: Gallimard, 2001.

.L'archéologie du savoir. France: Éditions Gallimard, 2004. 
Fornet-Betancourt, Raúl (2001). "Para un balance crítico de la filosofía iberoamericana en la llamada etapa de los fundadores". Utopía y Praxis Latinoamericana12. Año 6 (2001): $32-42$.

Horkheimer, Max. Crítica de la razón instrumental. Madrid: Editorial Trotta, 2002.

Jaksic, Iván. Rebeldes académicos. La filosofía chilena desde la Independencia hasta 1989. Santiago de Chile: Ediciones Universidad Diego Portales, 2013.

Lagmanovich, David. "Hacia una teoría del ensayo hispanoamericano". Eds. Isaac Jack Lévy y Juan Loveluck. El ensayo hispánico. Actas de Hispanic Studies 3(1984): 17-28.

Lukács, Georg. "Sobre la esencia y forma del ensayo". El alma y las formas. Barcelona: Grijalbo, 1975.

Mellafe, Rolando y González, María Teresa. El Instituto Pedagógico de la Universidad de Chile (1889-1981). Santiago: Universidad de Chile, 2007.

Miró Quezada, Francisco. Despertar y proyecto del filosofar latinoamericano. México: Fondo de Cultura Económica, 1974.

Molina Garmendia, Enrique. Filosofía Americana. Ensayos. Obras Completas. Vol. I. Comp. Miguel Da Costa Leiva. Concepción: Ediciones Universidad de Concepción, 19141994.

.La filosofía de Bergson (1916).Obras Completas. Vol. I. Comp. Miguel Da Costa Leiva. Concepción: Ediciones Universidad de Concepción, 1994.

.De lo espiritual en la vida humana. Vol. II. Comp. Miguel Da Costa Leiva. Concepción: Ediciones Universidad de Concepción, 1937-1994.

.Confesión filosófica y Llamado de superación a la América Hispana (1942). Vol. II. Comp. Miguel Da Costa Leiva. Concepción: Ediciones Universidad de Concepción, 1994. 
.Confesión personal (1943). Vol. IV. Comp. Miguel Da Costa Leiva.

Concepción: Ediciones Universidad de Concepción, 2000.

. Alejandro Venegas (Dr. Valdés Cange). Estudios y recuerdos. Santiago de Chile: Editorial Nascimiento, 1939.

- La filosofía en Chile en la primera mitad del siglo XX. Santiago de Chile: Editorial Nascimento, 1953.

.Lo que ha sido el vivir (Recuerdos y reflexiones). Prólogo de Mario Rodríguez Fernández. Cuadernos Atenea. $2^{\mathrm{a}}$ edición. Concepción: Editorial Universidad de Concepción, 2013.

De Onís, Federico. Antología de la poesía española e hispanoamericana. New York: Las Americas Publishing Company, 1961.

Ossandón B., Carlos. "La modernidad como experiencia en América Latina". Grafías filosóficas. Problemas actuales de la filosofía y su enseñanza. Olga Grau y Patricia Bonzi (editoras). Cátedra UNESCO de Filosofía y Facultad de Filosofía y Humanidades de la Universidad de Chile, 2008.

Pérez, Marcelo. Lecturas de Henri Bergson en América Latina (1900-1950). Texto inédito en elaboración, 2015.

Pozo, José Miguel. “El Congreso Nacional de Educación Secundaria de 1912 en la perspectiva de la evolución de la educación chilena". Dimensión histórica de Chile 6/7. Chile: Universidad Metropolitana de Ciencias de la Educación, 1989-1990.

Rabade, S. y otros. Historia de la filosofía. Madrid: G. del Toro Editor, 1978. Ramaglia, Dante. "Filosofía y praxis emancipatoria: una perspectiva para evaluar el proyecto intelectual de Alejandro Korn". Web. Feb. 2014.

. "Alejandro Korn y la "normalización" de la filosofía". Argentina entre el optimismo y el desencanto. Ed. Clara Jalif de Bertranou. Mendoza: Colección Cuadernos de Cuyo, 2007. 
Ramos, Julio. Desencuentros de la modernidad en América Latina. Literatura y política en el siglo XIX. México: Fondo de Cultura Económica, 2003.

Rancière, Jacques. El desacuerdo. Política y filosofía. Buenos Aires: Ediciones Nueva Visión, 1996. . Política de la literatura. Buenos Aires: Libros del Zorzal, 2011. .El reparto de lo sensible. Estética y política. Chile: Lom, 2009.

Raulet, Gérard. Walter Benjamin. Paris: Ellipses, 2000.

Rodó, José Enrique. Ariel. México: Editorial Porrúa, 1968.

Roig, Arturo Andrés. El espiritualismo argentino entre 1859 y 1900. México: Editorial Cajica, 1972.

Ruiz Stull, Miguel. Tiempo y experiencia. Variaciones en torno a Henri Bergson. Prólogo de Pablo Oyarzún. Chile: Fondo de Cultura Económica, 2013.

Sánchez, Cecilia. El conflicto entre la letra y la escritura. Legalidades / contralegalidades de la comunidad de la lengua en HispanoAmérica y América-Latina. Chile: Fondo de Cultura Económica, 2013.

Salas A., Ricardo. "La filosofía chilena del siglo XX como pensamiento crítico".Intus-Legere7.1 (2013): 9-25.

Salvat Boloña, Pablo. “Carencias y salvación de América según Enrique Molina". Comp. José Santos Herceg. Nuestra América inventada. Imágenes de América Latina en los pensadores chilenos. Chile, Usach: Ril editores, 2012. 